\title{
PREVENTION OF POSTOPERATIVE NAUSEA AND VOMITING IN ELECTIVE LSCS UNDER SPINAL ANAESTHESIA BY PRE-OPERATIVE ONDANSETRON VERSUS METOCLOPRAMIDE: A PROSPECTIVE SINGLE-BLINDED RANDOMISED CONTROL TRIAL
}

\author{
Prasada Rao Manem ${ }^{1}$, A. V. Sandeep Kumar D
}

${ }^{1}$ Associate Professor \& HOD, Department of Anaesthesia, Rajiv Gandhi Institute of Medical Sciences (RIMS), Srikakulam. ${ }^{2}$ Senior Resident, Department of Anaesthesia, Rajiv Gandhi Institute of Medical Sciences (RIMS), Srikakulam.

\section{ABSTRACT}

\section{CONTEXT}

Obstetric anaesthesia during modern day practice has become challenge for the anaesthesiologist as the patients are generally young women and expecting a smooth outcome, not only in terms of the baby born but also herself. The problem of PONV has become challenging, though appear small problem, tough to control postoperatively. Many drugs have been on trial, but not effective completely. Of late the central $5 \mathrm{HT}_{3}$ antagonists have been promising in achieving the objectives in comparison to the ones previously used.

\begin{abstract}
AIMS
To compare the efficacy and safety of prophylactic use of intravenous Metoclopramide (10mg) and Ondansetron (4mg) in preventing incidence of PONV, in patients undergoing elective LSCS under spinal anaesthesia.
\end{abstract}

\section{SETTINGS AND DESIGN}

A prospective randomized single blinded study conducted after obtaining written informed consent, 100 women patients aged above 18 years belonging to ASA grade I and II scheduled to undergo elective LSCS under spinal anaesthesia were enrolled in the study.

\section{METHODS AND MATERIAL}

Patients were randomly divided into 2 groups of 50 each. Group-M: received IV Metoclopramide 10mg. Group-0: received IV Ondansetron 4mg.

\section{STATISTICAL ANALYSIS USED}

'Z test' and Student's ' $\mathrm{t}$ ' test.

\section{RESULTS}

Number of episodes of emesis, nausea and retching were recorded at time intervals of $1 \mathrm{hr}, 2 \mathrm{hr}, 6 \mathrm{hr}$ and $24 \mathrm{hr}$ for all the patients in both groups. Incidence of Nausea was more in Group - M than Group - 0 at $1 \mathrm{hr}$ and $2 \mathrm{hr}$, but was statistically significant (p<0.05) at $2 \mathrm{hr}$ only. Incidence of vomiting was decreased in Group - 0 than Group - M, but was not statistically significant. Incidence of retching was more in the $1 \mathrm{hr}$ and $2 \mathrm{hr}$ in Group - M.

\section{CONCLUSION}

Fair to conclude that IV Ondansetron has proved a better prophylactic than IV Metoclopramide in preventing PONV for elective LSCS cases under spinal anaesthesia.

\section{KEYWORDS}

Obstetric Patient, Spinal Anesthesia, PONV (Post-Operative Nausea and Vomiting), Inj. Metoclopramide, Inj. Ondansetron.

HOW TO CITE THIS ARTICLE: Manem PR, A. V. Sandeep Kumar D. Prevention of postoperative nausea and vomiting in elective LSCS under spinal anaesthesia by pre-operative ondansetron versus metoclopramide: a prospective single-blinded randomised control trial. J. Evolution Med. Dent. Sci. 2016;5(16):785-789, DOI: 10.14260/jemds/2016/182

\section{INTRODUCTION}

Postoperative Nausea and Vomiting (PONV) is a seemingly simple problem, probably the most common complication of surgery performed under regional (or) general anaesthesia.

Financial or Other, Competing Interest: None.

Submission 14-01-2016, Peer Review 09-02-2016,

Acceptance 15-02-2016, Published 25-02-2016.

Corresponding Author:

Dr. Prasada Rao Manem,

Associate Professor \& HOD,

Department of Anaesthesia

RIMS, Srikakulam.

E-mail: prasad.manem79@gmail.com

DOI: $10.14260 /$ jemds/2016/182
One of the first extensive descriptions of the phenomenon of nausea and vomiting was by John Snow, published in 1848 within one and a half years of introduction of chloroform in Anaesthesia in Britain.

In spite of the advances like using less emetic anaesthetic agents, improved pre- and post-operative techniques and identification of patient predictive factors, nausea and vomiting still occur with unacceptable frequency in association with surgery and anaesthesia and is described as "the big little problem." PONV can be such an unpleasant experience that patients often rate it worse than postoperative pain. ${ }^{1-4}$ 
Causes of PONV are multifactional. Apfel and Colleagues. ${ }^{5}$ identified four major predictors of PONV: Female gender, nonsmoking status, previous history of PONV or motion sickness and the use of postoperative opioids.

Other factors which influence PONV are: Age, Hydration Status, Body Habitus, Medical Condition, Type of Anaesthesia, Duration of Anaesthesia, Type of Surgery and Postoperative Hypotension.

Nausea and vomiting during pregnancy: Parturients must always be considered to have a full stomach. The anatomical and physiological changes occurring in the gastrointestinal tract during pregnancy make regurgitation of gastric contents during anaesthesia more likely in gravid women than in non-pregnant patient. The rate of gastric emptying and transit time of bowel contents may be increased during pregnancy. The changes are heightened during labour by the effects of pain and anxiety, the recumbent position and opioid medications used for the systemic relief of pain. ${ }^{6}$

The likelihood of regurgitation is enhanced by the progressive pressure of the uterus and the abdominal contents on the stomach, changing its axis from the vertical to the horizontal. The tone of the gastro-oesophageal junction is decreased and pressure within the stomach is increased, particularly in lithotomy position. ${ }^{7}$ The hormonally induced reduction in gastric tone and motility make nausea, vomiting and gastro-oesophageal reflux more likely. ${ }^{8}$ although acid and pepsin secretions by stomach are diminished during major portion of pregnancy, toward term they tend to increase to above normal levels. ${ }^{9}$

At present newer antiemetics belonging to "specific $5 \mathrm{HT}_{3}$ subtype receptor antagonists," like ondansetron, granisetron are used to control PONV which are devoid of most of the side effects. The most common side effect of ondansetron is headache.

Metoclopramide is in use as antiemetic for many years but Ondansetron is being used recently. A comparative effectiveness of these two drugs in reducing and preventing incidence of PONV in LSCS under spinal anaesthesia were evaluated in this study.

\section{SUBJECTS AND METHODS}

A prospective randomized single blinded study performed after obtaining written informed consent, 100 women patients aged above 18 years belonging to ASA grade I and II scheduled to undergo elective LSCS under spinal anaesthesia were enrolled in the study. Patients were randomly allocated into two groups.

The selection of patients were carried out randomly. Patients were explained in their own language the anaesthetic procedure they are going to undergo. Pre-anaesthetic examination was done prior to the day of surgery.

A specially designed proforma was used to collect the data which includes patient's particulars, indication for surgery, the anaesthetic details, intraoperative monitoring, observation for side effects, etc.

Patients were divided into 2 groups of 50 each by simple randomization and single blinded technique. Group-M: received IV Metoclopramide 10mg. Group-0: received IV Ondansetron 4mg.

Each patient received their study drug 3-5 minutes before subarachnoid block.

\section{RESULTS}

\section{Emesis}

Number of episodes of emesis at 1 hr., 2 hrs. 6 hrs. and $24 \mathrm{hrs}$. were recorded and are shown in Table 1 and Chart 1 . Comparison of emesis mean episodes between $1 \mathrm{hr} .2 \mathrm{hr}$., $6 \mathrm{hr}$. and $24 \mathrm{hr}$. are shown in Table 2.

Though Group-O has shown less number of emetic episodes in $1 \mathrm{hr}$. and $2 \mathrm{hrs}$. than Group-M, it was not statistically significant.

\section{Nausea}

Nausea was graded as:

$0=$ None, $1=$ Mild, $3=$ Moderate, $3=$ Severe

Comparison of nausea grades are shown in Table 3 and Chart 2. Comparison of nausea mean grades are tabulated in Table 4. Incidence of nausea was more in $1^{\text {st }}$ hour in both groups. The nausea grading was significantly low in the Group-0 compared to Group-M at $1 \mathrm{hr}$. and $2 \mathrm{hrs}$.

\section{Retching}

It is defined as dry heaves. They were also recorded as the number of episodes. The total number of retching in 5 minutes were taken as one episode.

The findings were tabulated in Table 5 and 6 and represented in Chart 3.

Frequencies of PONV and retching were tabulated in Table 7 and graphically represented in Charts 4,5 and 6 . Incidence of Nausea was more in Group-M than Group-0 at 1 $\mathrm{hr}$ and $2 \mathrm{hrs}$, but was statistically significant at $2 \mathrm{hrs}$ only. Incidence of Vomiting was decreased in Group-O than Group-M, but was not statistically significant. Incidence of Retching was more in the $1 \mathrm{hr}$ and $2 \mathrm{hrs}$ in Group M.

A $14 \%$ of Group-M patients experienced retching, while 8\% of Group-0 patients experienced retching. Incidence of retching was reduced significantly in the group- 0 patients at 2 hrs.

Severe nausea and vomiting were labelled as failure and rescue therapy was initiated with IV ondansetron or metoclopramide respectively and with IV fluids.

\begin{tabular}{|c|c|c|}
\hline \multicolumn{3}{|c|}{ EMESIS (EPISODES) } \\
\hline & Group M & Group 0 \\
\hline $1 \mathrm{hr}$ & 14 & 7 \\
\hline $2 \mathrm{hr}$ & 4 & 3 \\
\hline $6 \mathrm{hr}$ & 1 & 0 \\
\hline $24 \mathrm{hr}$ & 0 & 0 \\
\hline \multicolumn{2}{|c|}{ Table 1: Comparison of Emesis (Episodes) } \\
\hline
\end{tabular}

\begin{tabular}{|c|c|c|c|c|c|c|c|}
\hline \multicolumn{1}{|c|}{ COMPARISON OF EMESIS (MEAN EPISODES) } \\
\cline { 1 - 5 } & Group M & \multicolumn{2}{c|}{ Group O } & $\begin{array}{c}\text { Z- } \\
\text { Value }\end{array}$ & $\begin{array}{c}\text { P- } \\
\text { Value }\end{array}$ & Remarks \\
\hline & Mean & S.D & Mean & S.D & RS \\
\hline $1 \mathrm{hr}$ & 0.28 & 0.57 & 0.14 & 0.40 & 1.72 & 0.08 & NS \\
\hline $2 \mathrm{hr}$ & 0.08 & 0.27 & 0.06 & 0.24 & 0.39 & 0.69 & NS \\
\hline $6 \mathrm{hr}$ & 0.02 & 0.14 & 0 & 0 & 1.00 & 0.31 & NS \\
\hline $24 \mathrm{hr}$ & 0.0 & 0.0 & 0 & 0 & & & \\
\hline \multicolumn{7}{|c|}{ Table 2: Comparison of Emesis (Mean Episodes) } \\
\hline
\end{tabular}

\begin{tabular}{|c|c|c|}
\hline \multicolumn{3}{|c|}{ NAUSEA (GRADES) } \\
\hline & Group M & Group 0 \\
\hline $1 \mathrm{hr}$ & 32 & 16 \\
\hline $2 \mathrm{hr}$ & 13 & 3 \\
\hline $6 \mathrm{hr}$ & 1 & 0 \\
\hline $24 \mathrm{hr}$ & 0 & 0 \\
\hline \multicolumn{2}{|c|}{ Table 3: Comparison of Nausea (Grades) } \\
\hline
\end{tabular}




\begin{tabular}{|c|c|c|c|c|c|c|c|}
\hline \multicolumn{8}{|c|}{ COMPARISON OF NAUSEA (MEAN GRADES) } \\
\hline & \multicolumn{2}{|c|}{ Group M } & \multicolumn{2}{|c|}{ Group 0} & \multirow{2}{*}{$\begin{array}{c}\text { Z- } \\
\text { Value }\end{array}$} & \multirow{2}{*}{$\begin{array}{c}\text { P- } \\
\text { Value }\end{array}$} & \multirow{2}{*}{$\begin{array}{c}\text { Re- } \\
\text { marks }\end{array}$} \\
\hline & Mean & S.D & Mean & S.D & & & \\
\hline $1 \mathrm{hr}$ & 0.64 & 0.83 & 0.32 & 0.55 & 3.20 & 0.001 & $S$ \\
\hline $2 \mathrm{hr}$ & 0.26 & 0.53 & 0.06 & 0.24 & 2.73 & 0.006 & $\mathrm{~S}$ \\
\hline $6 \mathrm{hr}$ & 0.02 & 0.14 & 0 & 0 & 1.005 & 0.31 & NS \\
\hline $24 \mathrm{hr}$ & 0 & 0 & 0 & 0 & & & \\
\hline \multicolumn{8}{|c|}{ Table 4: Comparison of Nausea (Mean Grades) } \\
\hline
\end{tabular}

\begin{tabular}{|c|c|c|}
\hline \multicolumn{3}{|c|}{ RETCHING (EPISODES) } \\
\hline & Group M & Group 0 \\
\hline $1 \mathrm{hr}$. & 6 & 4 \\
\hline $2 \mathrm{hr}$. & 6 & 0 \\
\hline $6 \mathrm{hr}$. & 0 & 0 \\
\hline $24 \mathrm{hr}$. & 0 & 0 \\
\hline \multicolumn{2}{|c|}{ Table 5: Comparison of Retching (Episodes) } \\
\hline
\end{tabular}

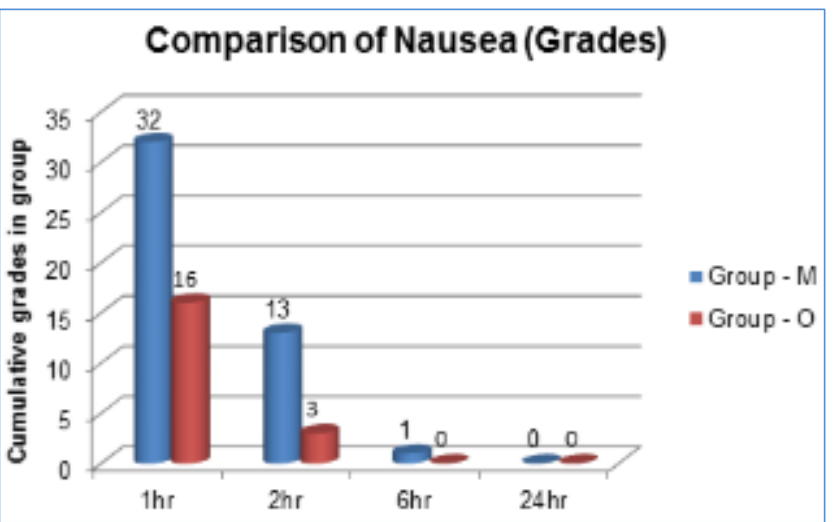

Chart 2: Comparison of Nausea (Grades)

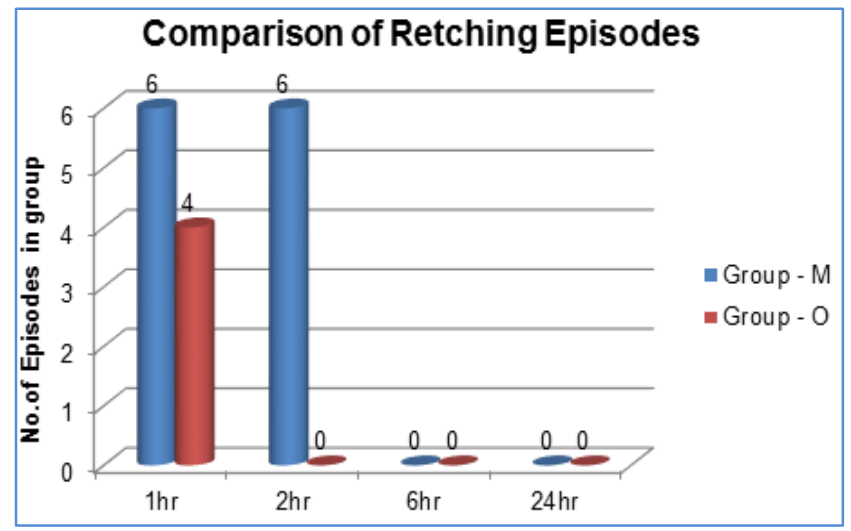

Table 6: Comparison of Retching (Mean Episodes)

\begin{tabular}{|c|c|c|c|c|c|c|c|}
\hline \multicolumn{7}{|c|}{ COMPARISON OF RETCHING (MEAN EPISODES) } \\
\hline & Group M & \multicolumn{2}{c|}{ Group O } & $\begin{array}{c}\text { Z- } \\
\text { Value }\end{array}$ & $\begin{array}{c}\text { P- } \\
\text { Value }\end{array}$ & $\begin{array}{c}\text { Re- } \\
\text { Marks }\end{array}$ \\
\hline & Mean & S.D & Mean & S.D & 0.50286 & NS \\
\hline $1 \mathrm{hr}$ & 0.12 & 0.33 & 0.08 & 0.27 & 0.6667 & 0.506 & $\mathrm{~S}$ \\
\hline $2 \mathrm{hr}$ & 0.12 & 0.33 & 0 & 0 & 2.5265 & 0.0114 & \\
\hline $6 \mathrm{hr}$ & 0 & 0 & 0 & 0 & & & \\
\hline $24 \mathrm{hr}$ & 0 & 0 & 0 & 0 & & & \\
\hline \multicolumn{7}{|c|}{ Table 6: Comparison of Retching (Mean Episodes) } \\
\hline
\end{tabular}

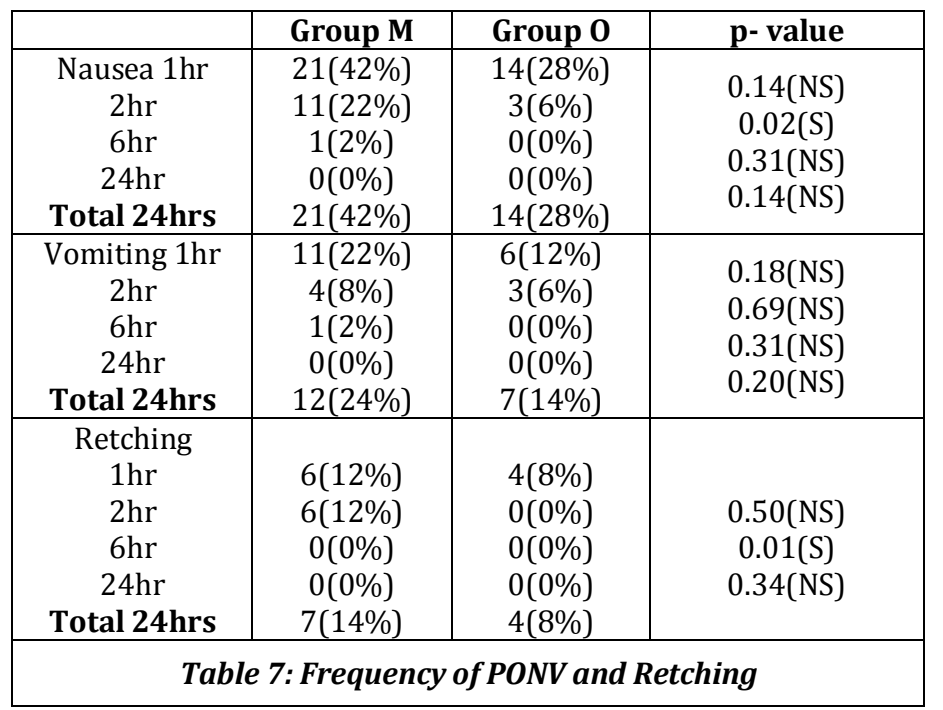

Chart 3: Comparison of Retching (Episodes)

\section{Chart 4 : Frequency of Nausea}

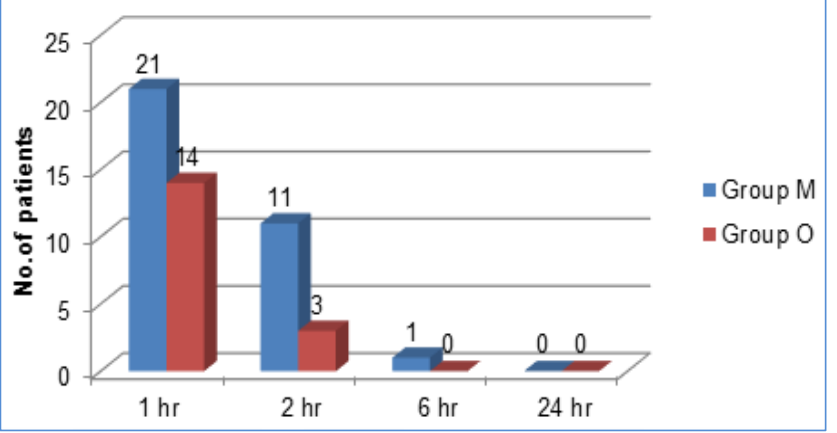

Chart 4: Frequency of Nausea

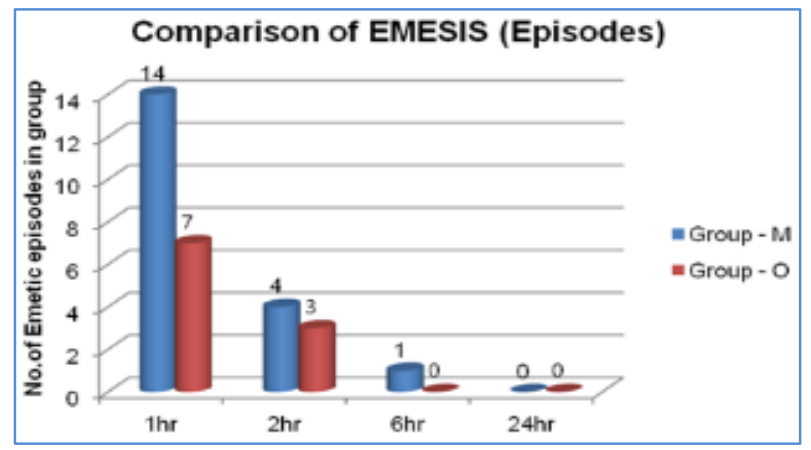

Chart 1: Comparison of Emesis (Episodes)

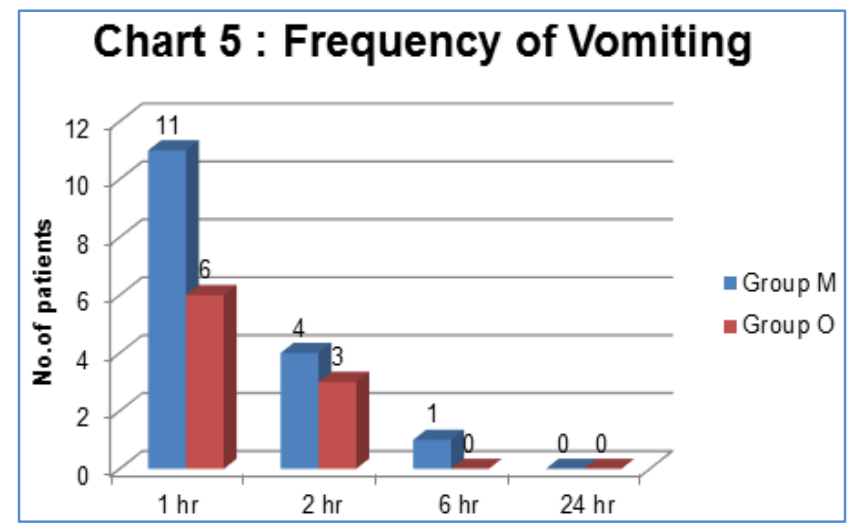

Chart 5: Frequency of Vomiting 


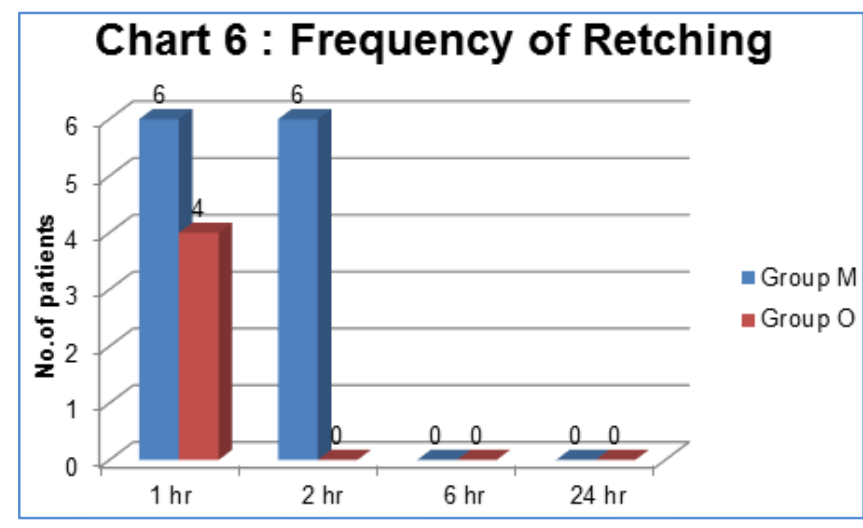

Chart 6: Frequency of Retching

\section{Side Effects}

In the Group-M, one patient had extrapyramidal syndrome, which was treated with IV diazepam.

In the Group-O, one patient complained of headache.

\section{DISCUSSION}

PONV is the most distressing and unpleasant experience for a patient who is anaesthetised for surgery. Furthermore, severe postoperative emesis may lead to dehydration, electrolyte imbalance, which in turn may alter the overall outcome of the entire surgical procedure. Postoperative vomiting may though rarely lead to a life-threatening complication like aspiration pneumonitis.

In spinal anaesthesia for LSCS, hypotension, manipulation of abdominal viscera and hormonal influences are strong emetic stimuli. Pain, anxiety and drugs like opioids, NSAID's also have been implicated in postoperative vomiting.

There are many drugs used for treatment of PONV like metoclopramide, domperidone, phenothiazines, butyrophenones, anticholinergics and antihistamines. Even though these drugs have either alone or in combination have been proved effective to a certain extent, a search was on for a newer antiemetic drug, which leads to the invention of $5-\mathrm{HT}_{3}$ antagonist, ondansetron.

Studies comparing many of these drugs with ondansetron have been carried out from years (since 1991). It was evident that ondansetron was highly or equally effective in preventing PONV in some studies. But the incidence of side effects were low with ondansetron, whereas with most of the other drugs the incidence of side effects were high like extrapyramidal symptoms (eg. Metoclopramide, domperidone, perphenazine, droperidol), haematological abnormalities (eg: prochlorperazine), sedation (eg: chlorpromazine, droperidol, cyclizine, etc.) and adverse cardiovascular effects (eg: metoclopramide, chlorpromazine, etc.)

In this study, we compared the efficacy and safety of IV ondansetron and metoclopramide as prophylactics for PONV in elective LSCS under spinal anaesthesia.

In a randomized, double-blind study by Rabey PG, Smith G. 10 to compare the prophylactic antiemetic efficacy of ondansetron with droperidol and metoclopramide in 66 patients undergoing general anaesthesia for dilatation and curettage. The incidence of vomiting was $13 \%$ with ondansetron, $45 \%$ with droperidol and $54 \%$ with metoclopramide $(\mathrm{P}<0.05)$.
The comparative study by Alexander R, Fennelly M.11 for the incidence of postoperative nausea and vomiting in 124 patients undergoing major lower limb orthopaedic surgery in a randomized double blind study following oral premedication with temazepam and ondansetron $8 \mathrm{mg}$, metoclopramide $10 \mathrm{mg}$ or placebo. The incidence of nausea and vomiting significantly decreased in the ondansetron group $(\mathrm{P}=0.03)$.

Helmy SAK. ${ }^{12}$ evaluated the prophylactic antiemetic efficacy and safety of preoperative intravenous ondansetron in a randomized, double blind comparison with droperidol, metoclopramide and placebo in 160 patients undergoing laparoscopic cholecystectomy under total intravenous anaesthesia. He reported the incidence of nausea and vomiting was significantly lower $(\mathrm{p}<0.05)$ between 1 hour and 4 hours after surgery in the ondansetron group compared with droperidol, metoclopramide and placebo groups and overall incidence of nausea and vomiting was lower during the first 24 hours after surgery in this group.

In the study by Pan PH, et al. ${ }^{13}$ of prevention of PONV after LSCS under epidural anaesthesia proved that ondansetron $4 \mathrm{mg}$ IV is more effective in preventing nausea than metoclopramide $10 \mathrm{mg}$ and achieving complete and major responses during the intraoperative period and the overall 24hour study period. The cumulative nausea and vomiting scores per patient (a measure of severity of emetic symptoms in each group) for the 24-hour study period and the intraoperative period were significantly lower in Group $0(3.0 \pm 6,2.7 \pm 5.5$, respectively) than Group P $(15.3 \pm 19.9,11.8 \pm 17$, respectively) ( $p$ <.001); but the differences between Groups 0 and $M$ and between Groups $\mathrm{M}$ and $\mathrm{P}$ were insignificant.

The need for use of emesis basins in the overall 24-hour period was significantly less for Group 0 (15\%) compared to Group M (33\%) and in turn significantly less than Group P $(55 \%)(p<0.03)$. Significantly more patients in Group O (74\%) rated the overall patient satisfaction as excellent compared with Group M (53\%) and in turn significantly more than Group $\mathrm{P}(37 \%)$.

In the study by Paxton et al. ${ }^{14}$ of prevention of nausea and vomiting after day care gynaecological laparoscopy, observed that ondansetron is superior for prophylaxis against PONV than metoclopramide. The scores for nausea were significantly lower in the ondansetron group $(p<0.01)$ compared with the other three groups at 1,2 and $4 \mathrm{hrs}$ after operation; thereafter there was no difference. The incidence of emesis was lower $(p=0.063)$ and time to first oral fluids was shorter $(p<0.05)$ in the ondansetron group.

In this study $86 \%$ of ondansetron group patients were emesis episodes free, while in metoclopramide group $76 \%$ patients experienced no emesis. The incidence of emesis was significantly lower in ondansetron group ( $p<0.01)$. The incidence of vomiting was more at 1 hour and 2 hours in both groups and incidence was less in ondansetron group $(\mathrm{p}=0.08)$ at both time intervals. Severity of vomiting also was less in ondansetron group than metoclopramide group.

In this study retching was observed separately from vomiting. The incidence of retching was less in ondansetron group than metoclopramide group; $92 \%$ experienced no retching in ondansetron group, while it was $86 \%$ in metoclopramide group. This observation was very significant at 2 hours. Severity also was less in ondansetron group.

Nausea control was significant with incidence in metoclopramide group $40 \%$, which reduced to $28 \%$ in the 
ondansetron group and severity of nausea was less in ondansetron group than metoclopramide group.

Incidence of PONV was very less at 6 hours and 24 hours in both groups. This study proved that ondansetron significantly reduced the incidence of PONV at 1 hour and 2 hours than metoclopramide.

\section{Side Effects}

While the purpose of using prophylactic drug is to prevent PONV, it is imperative that drugs used do not compromise the patient's condition due to the side effects. Drugs commonly used like metoclopramide, droperidol, domperidone are associated with sedation, hypotension and extrapyramidal symptoms.

In a study by Dupreyron JP, et al.15 they observed low incidence of side effects with ondansetron. Headache and constipation being the most common side effects.

In another study by Scuderi P, et al. ${ }^{16}$ they found no side effects with ondansetron.

The side effects in this study were very low with one patient had extrapyramidal syndrome in metoclopramide group, which was treated with IV diazepam and one patient complained of headache in ondansetron group, which relieved without any treatment. Thus ondansetron was much more effective in decreasing the PONV in LSCS under subarachnoid block with low side effect profile.

\section{CONCLUSION}

It is fair to conclude from this study that IV ondansetron, a $5 \mathrm{HT}_{3}$ antagonist in the dose of $4 \mathrm{mg}$ has proved as a better prophylactic drug than IV metoclopramide $10 \mathrm{mg}$ in prevention of PONV in LSCS under spinal anaesthesia.

\section{REFERENCES}

1. Kerger H, Turan A, Kredel M, et al. Patient's willingness to pay for anti-emetic treatment. Acta Anaesthesiol Scand 2007;51:38-43.

2. Craigo PA, Paul A. "Gastrointestinal physiology: aspiration of gastric contents; postoperative nausea and vomiting." Chapter 21. Collins VJ: "Physiologic and pharmacological bases of anaesthesia." 1st Edn., Baltimore, Williams and Wilkins, 1996;361-394.

3. Macario A, Weinger M, Carney S, et al. Which clinical anaesthesia outcomes are important to avoid? The perspective of patients. Anaesth Analg 1999;89:652-658.
4. Gan T, Sloan F, Dear G, et al. How much are patients willing to pay to avoid postoperative nausea and vomiting? Anaesth Analg 2001;92:393-400.

5. Apfel CC, Roewer N, Korttila K. How to study postoperative nausea and vomiting. Acta Anaesthesiol Scand 2002;46:921-928.

6. Nimmo WS, Wilson J, Prescott LF. Narcotic analgesics and delayed gastric emptying during labour. Lancet 1975;1:890-893.

7. Brock-Utne JG, Dow TGB, Welman S. The effect of metoclopramide on the lower oesophageal sphincter in late pregnancy. Anaesthesia and Intensive Care 1978;6:2629.

8. Vanner RG, Good Man NW. Gastro-oesophageal reflux in pregnancy at term and after delivery. Anaesthesia 1989;44:808-811.

9. Attia RR, Ebeid AM, Fischer JE. Maternal, fetal and placental gastrin concentrations. Anaesthesia 1982;37:18-21.

10. Rabey PG, Smith G. "Anaesthetic factors contributing to postoperative nausea and vomiting." $\mathrm{Br} \mathrm{J}$ Anaesth, 1992;69:40S-45S.

11. Alexander R, Fennelly M. "Comparison of ondansetron, metoclopramide and placebo as premedicants to reduce nausea and vomiting after major surgery." Anaesthesia 1997;52:695-703.

12. Helmy SAK._-Prophylactic antiemetic efficacy of ondansetron in laparoscopic cholecystectomy under total intravenous anaesthesia." Anaesthesia 1999;54:266-296.

13. Pan PH, Moore CH. Comparing the efficacy of prophylactic metoclopramide, Ondansetron and placebo in caesarean section patients giving epidural anaesthesia. J Clin Anaesth 2001;13(6):430-5.

14. Paxton LD, McKay AC, Mirakhur RK. "Prevention of nausea and vomiting after day care gynaecological laparoscopy." Anaesthesia 1995;50:403-406.

15. Dupreyron JP, Conseiller C, Levarlet M. "The effect of oral ondansetron in the prevention of postoperative nausea and vomiting after major gynaecological surgery performed under general anaesthesia." Anaesthesia 1993;48:214-218.

16. Scuderi P, Wetchler B, Fong-Sung Y. "Double-blind, randomized comparison of ondansetron and intraoperative propofol to prevent postoperative nausea and vomiting." Anaesthesiology 1993;78:15-20. 